\title{
Effect of daylength on the rate of recovery of photosensitivity in male starlings (Sturnus vulgaris)
}

\author{
A. Dawson \\ NERC Institute of Terrestrial Ecology, Monks Wood Experimental Station, Abbots Ripton, \\ Huntingdon, PE17 2LS, UK
}

\begin{abstract}
Summary. Four groups of castrated photorefractory starlings were transferred from a photoperiod of $18 \mathrm{~h}$ light/day $(18 \mathrm{~L})$ to photoperiods of $6 \mathrm{~L}, 8 \mathrm{~L}, 11 \mathrm{~L}$ or $12 \mathrm{~L}$. A control group was kept on $18 \mathrm{~L}$. Plasma concentrations of luteinizing hormone (LH) were low in all groups initially. The first significant increase in $\mathrm{LH}$, which signals the recovery of photosensitivity, occurred after 4 weeks in the groups on $6 \mathrm{~L}$ and $8 \mathrm{~L}$, after 8 weeks in the $11 \mathrm{~L}$ group and after 13 weeks in the $12 \mathrm{~L}$ group. There was no increase in the group on $18 \mathrm{~L}$. The rate of recovery of photosensitivity is therefore inversely proportional to daylength, for daylengths between $8 \mathrm{~L}$ and $12 \mathrm{~L}$.
\end{abstract}

Keywords: photoperiodism; photosensitivity; luteinizing hormone; starling

\section{Introduction}

Seasonal reproduction in birds from mid-high latitudes ends as birds become photorefractory. Photorefractoriness is caused by long days and either results in spontaneous gonadal regression while days are still long (Burger, 1947) or predisposes birds to gonadal regression as daylength decreases (Robinson \& Follett, 1982). Under experimental circumstances, the longer the daylength, the sooner birds become refractory (Hamner, 1971; Harris \& Turek, 1982; Dawson \& Goldsmith, 1983; Moore et al., 1983).

The termination of refractoriness and consequent recovery of photosensitivity occurs under short days (Wolfson, 1952), but the importance of the length of the short day is unclear. Short days may actively drive the physiological process leading to recovery of photosensitivity, in which case this would occur more rapidly under shorter days. Alternatively, any daylength less than one perceived as long, may permit the process to progress at a rate independent of daylength. Although the rate of development of photorefractoriness is proportional to daylength, this is probably only true when days exceed a critical length. In starlings, days of $11 \mathrm{~h}$ of light or less cause no progression towards photorefractoriness (Dawson, 1989). This may imply that the rate of recovery of photosensitivity is independent of daylength. This may be true for house finches (Hamner, 1968), but it is not true for canaries (Nicholls \& Storey, 1977).

In intact birds, the transition from the photorefractory state to the photosensitive state, under short days, is not obvious; birds have to be transferred to long days to determine whether they have become photosensitive. However, in castrated birds of several species (Nicholls et al., 1988), the termination of photorefractoriness is apparent as an increase in circulating luteinizing hormone (LH). This is particularly true of starlings, in which plasma LH increases from minimal to maximal concentrations as refractoriness is terminated under short days (Goldsmith \& Nicholls, 1984). In the following experiment, castrated photorefractory starlings were transferred to short days of various lengths to determine the timing of this $\mathrm{LH}$ increase. 


\section{Materials and Methods}

Starlings were caught from the wild using baited traps during August. Only juvenile birds, i.e. hatched earlier in the same year, were used; these can be distinguished from adults at this time of year by their plumage. This ensured that all birds were the same age. The birds were kept in outdoor aviaries with food (chick starter crumbs, Whetstones, St Ives, Cambs., UK) and water was provided ad libitum.

In late February, 42 males were moved indoors and kept in aluminium cages $(0.6 \times 0.5 \times 0.4 \mathrm{~m})$ with 4-5 birds/ cage. Daylength was $12 \mathrm{~h}$ light and $12 \mathrm{~h}$ darkness/day (12 L:12 D), ambient at that time. These birds were castrated; they were anaesthetized with an i.m. injection of metomidate (Hypnodil: Veterinary Drug Co., Dunnington, York, UK), an incision was made between the last pair of ribs and both testes were removed with fine curved forceps.

Daylength was increased to $18 \mathrm{~L}: 6 \mathrm{D}$ at the end of February. Under this daylength, starlings become photorefractory after $\sim 6$ weeks (Dawson \& Goldsmith, 1983). Moult began after 8 weeks and was almost complete by 16 weeks. At this time, a blood sample was taken from each bird; $\sim 800 \mu \mathrm{l}$ was collected into a heparinized tube after pricking the wing vein. The birds were randomly divided into 5 groups of 8 individuals ( 2 birds had died). One group (Group 18) was left on $18 \mathrm{~L}: 6 \mathrm{D}$, others were transferred to $12 \mathrm{~L}: 12 \mathrm{D}, 11 \mathrm{~L}: 13 \mathrm{D}, 8 \mathrm{~L}: 16 \mathrm{D}$ or $6 \mathrm{~L}: 18 \mathrm{D}$ (Groups 12,11, 8 and 6 respectively). Further blood samples were collected at intervals over the next 13 weeks. Blood was centrifuged at $1000 \mathrm{~g}$ for $10 \mathrm{~min}$ and plasma was stored at $-20^{\circ} \mathrm{C}$.

LH assay. The assay used was that of Follett et al. (1972) using an antiserum (anti-IRC2T) raised against chicken LH. Duplicate $20-\mu$ l plasma samples were measured in a single assay. The intra-assay coefficient of variance was $8 \%$ $(n=8)$, sensitivity was $0.1 \mu \mathrm{g} / 1$ and $50 \%$ binding was at $2.9 \mu \mathrm{g} / \mathrm{l}$.

Statistical analysis. Differences with time within groups were assessed using ANOVA with repeated measures, followed by Newman-Keuls tests. Differences between groups at the same time were assessed by single-factor ANOVA, followed by Newman-Keuls tests.

\section{Results}

In all groups transferred to shorter daylengths, plasma $\mathbf{L H}$ concentrations increased significantly $(\mathrm{F}(8,56)=37.7$ in Group 6, 31.2 in Group 8, 39.6 in Group 11 and 4.63 in Group 12, $P<0.0002)$, indicating that birds in these groups became photosensitive (Fig. 1). However, the time taken for

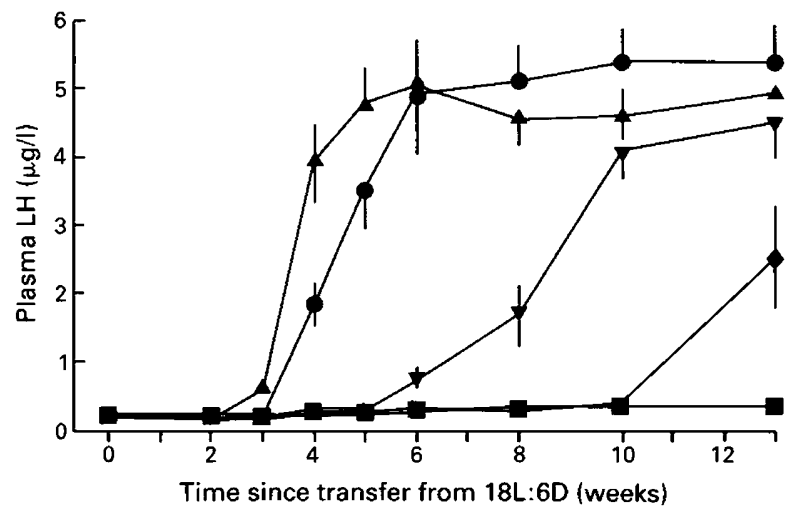

Fig. 1. Plasma concentration of luteinizing hormone $(\mathrm{LH})$ in groups of photorefractory starlings kept in a daylength of $18 \mathrm{~h}$ of light: $6 \mathrm{~h}$ dark/day $(18 \mathrm{~L})$, or transferred at week 0 from $18 \mathrm{~L}(\mathbf{\square})$ to $6 \mathrm{~L}(\Delta), 8 \mathrm{~L}(\bullet), 11 \mathrm{~L}(\nabla)$ or $12 \mathrm{~L}(\bullet)$. Each point represents the mean \pm s.e.m. for 8 birds. Where error bars are not shown, they were smaller than the size of the symbol.

the recovery of photosensitivity varied with daylength. In Groups 6 and 8 , the first significant increase in LH was 4 weeks after transfer $(P<0.01$ and $<0.05$, respectively), but, at this time $\mathrm{LH}$ was significantly higher $(P<0.01)$ in Group 6 than in Group 8, suggesting that the recovery of photosensitivity may have occurred marginally earlier under $6 \mathrm{~L}: 18 \mathrm{D}$ than under $8 \mathrm{~L}: 16 \mathrm{D}$. Under the other 2 daylengths, recovery of photosensitivity was greatly delayed. The first significant 
$(P<0.01)$ increase in LH was at 8 weeks in Group 11 and at 13 weeks in Group 12. In Group 18, plasma LH remained low throughout the experiment.

\section{Discussion}

Two previous studies attempted to determine the importance of the length of short days on the rate of recovery of photosensitivity. In both, recovery of photosensitivity was assessed by transferring intact males to long days after exposure to short days. Hamner (1968) showed that in house finches (Carpodacus mexicanus) daylengths of $8 \mathrm{~L}: 16 \mathrm{D}, 10 \mathrm{~L}: 14 \mathrm{D}, 12 \mathrm{~L}: 12 \mathrm{D}$ and $14 \mathrm{~L}: 10 \mathrm{D}$ terminated photorefractoriness at an equal rate. In contrast, Nicholls \& Storey (1977) found that in canaries (Serinus canarius) the rate under $8 \mathrm{~L}: 16 \mathrm{D}$ exceeded that under $11 \mathrm{~L}: 13 \mathrm{D}$. This discrepancy may be due to a genuine species difference, but in Hamner's experimental design a real difference in rate may not have been revealed.

In the present study, LH was measured in castrated starlings, to avoid the need to transfer birds to long days. The results clearly demonstrate that photosensitivity is re-acquired more rapidly under $6 \mathrm{~L}: 18 \mathrm{D}$ and $8 \mathrm{~L}: 16 \mathrm{D}$ than under $11 \mathrm{~L}: 13 \mathrm{D}$ and that the rate under $11 \mathrm{~L}: 13 \mathrm{D}$ exceeds that under $12 \mathrm{~L}: 12 \mathrm{D}$. Birds transferred to $12 \mathrm{~L}: 12 \mathrm{D}$ did eventually become photosensitive after $\sim 13$ weeks. This may be the longest photoperiod under which photosensitivity is recovered. In another study (Dawson, 1987), starlings transferred from 18 L:6 D to $13 \mathrm{~L}: 11 \mathrm{D}$ remained photorefractory for at least 18 weeks. Under $18 \mathrm{~L}: 6 \mathrm{D}$, birds had not become photosensitive by 13 weeks and such birds are known to remain photorefractory for at least 2 years (A. Dawson, unpublished data).

From the results presented here, it is not clear whether the rate of recovery of photosensitivity is dependent on the absolute length of the short day, or on the magnitude of the decrease in daylength. However, in an earlier study (Dawson, 1987), birds transferred from 18 L:6 D or 13 L:11 D to $8 \mathrm{~L}: 16 \mathrm{D}$, i.e. decreases of $10 \mathrm{~h}$ or $5 \mathrm{~h}$, became photosensitive at the same rate, showing that the differences in the rate of recovery of photosensitivity are due to the absolute length of the short day, and not to the magnitude of the decrease in daylength.

The first significant increase in $\mathrm{LH}$ occurred at the same time in birds transferred to $8 \mathrm{~L}: 16 \mathrm{D}$ and $6 \mathrm{~L}: 18 \mathrm{D}$, but the results suggest that the recovery of photosensitivity may have been slightly earlier under $6 \mathrm{~L}: 18 \mathrm{D}$. There may be a daylength, possibly $\sim 6 \mathrm{~L}$, beyond which any further shortening has no effect on the rate of recovery. In other words, the process leading to the increase in $\mathrm{LH}$ cannot be driven any faster under such shorter daylengths.

In conclusion, the rate of recovery of photosensitivity depends on the length of the short day. Days of $13 \mathrm{~L}$ or longer do not result in recovery of photosensitivity. For daylengths between $12 \mathrm{~L}$ : $12 \mathrm{D}$ and $8 \mathrm{~L}: 16 \mathrm{D}$, the rate of recovery is inversely proportional to daylength. It is unclear whether daylengths less than $8 \mathrm{~L}: 16 \mathrm{D}$ result in an even faster rate of recovery.

I am indebted to Professor B. K. Follett and Dr A. R. Goldsmith of the AFRC Research Group on Photoperiodism \& Reproduction, University of Bristol, for facilities for measuring LH.

\section{References}

Burger, J.W. (1947) On the relation of daylength to the phases of testicular involution and inactivity of the spermatogenic cycle of the starling. J. exp. Zool. 105, 259-267.

Dawson, A. (1987) Photorefractoriness in European starlings: critical daylength is not affected by photoperiodic history. Physiol. Zool. 60, 722-729.

Dawson, A. (1989) The involvement of thyroxine and daylength in the development of photorefractoriness in European starlings. J. exp. Zool. 249, 68-75.
Dawson, A. \& Goldsmith, A.R. (1983) Plasma prolactin and gonadotrophins during gonadal development and the onset of photorefractoriness in male and female starlings (Sturnus vulgaris). J. Endocr. 97, 253-260.

Follett, B.K., Scanes, C.G. \& Cunningham, F.J. (1972) A radioimmunoassay for avian luteinizing hormone. $J$. Endocr. 52, 359-378.

Goldsmith, A.R. \& Nicholls, T.J. (1984) Recovery of photosensitivity in photorefractory starlings is not 
prevented by testosterone treatment. Gen. comp. Endocr. 56, 210-217.

Hamner, W.M. (1968) The photorefractory period of the house finch. Ecology 49, 211-227.

Hamner, W.M. (1971) On seeking an alternative to the endogenous reproductive rhythm hypothesis in birds. In Biochronometry, pp. 448-461. Ed. M. Menaker. National Academy of Sciences, Washington DC.

Harris, M.O. \& Turek, F.E. (1982) Photoperiodic control of the timing of testicular regression in white-throated sparrows. Gen. comp. Endocr. 46, $124-129$.

Moore, M.C., Schwabl, H. \& Farner, D.S. (1983) Biochronometry of testicular regression in whitecrowned sparrows (Zonotrichia leucophrys gambelii). J. comp. Physiol. 153, 489-494.
Nicholls, T.J. \& Storey, C.R. (1977) The effect of duration of the daily photoperiod on recovery of photosensitivity in photorefractory canaries (Serinus canarius). Gen. comp. Endocr. 31, 72-74.

Nicholls, T.J., Goldsmith, A.R. \& Dawson, A. (1988) Photorefractoriness in birds and comparison with mammals. Physiol. Rev. 68, 133-176.

Robinson, J.E. \& Follett, B.K. (1982) Photoperiodism in Japanese quail: the termination of seasonal breeding by photorefractoriness. Proc. R. Soc. Lond., B. 215, 95-116.

Wolfson, A. (1952) The occurrence and regulation of the refractory period in the gonadal and fat cycles of the junco. J. exp. Zool. 121, 311-325.

Received 8 January 1991 